\title{
PERANCANGAN SISTEM INFORMASI KASIR KEDAI KOPI PEJUANG JAKARTA
}

\author{
Abdul Rasyid', Halimatus Sa'diah² \\ ${ }^{1,2}$ Teknik Informatika, Fakultas Teknik dan Ilmu Komputer, Universitas Indraprasta PGRI \\ Jalan Raya Tengah No 80, Kelurahan Gedong, Pasar Rebo, Jakarta Timur \\ 1.Arasyid202@gmail.com, 22gbhock300679@gmail.com
}

\begin{abstract}
ABSTRAK
Kedai kopi pejuang yang berlokasi di Jl. Kebagusan raya 1D, Jakarta Selatan. Sistem informasi kasir pada kedai kopi pejuang masih dilakukan secara manual, pengelola sulit menghitung nilai pemasukan dan pengeluaran. Dengan memanfaatkan teknologi informasi saat ini yang dapat dipadukan dengan sistem yang sudah terkomputerisasi sehingga dapat membantu kinerja karyawan sehingga dapat bekerja secara efektif dan efisien. Metode penelitian yang penulis gunakan adalah Grounded Research, secara umum adalah pengembangan dan penelitian dalam bidang teknologi. Tujuan penelitian adalah untuk merancang penggunaan Sistem Informasi Kasir dan memudahkan pihak kedai dalam mengelolah data transaksi dan stok barang. Sistem informasi kasir menggunakan Bahasa pemograman Java dan juga menggunakan Xampp dan MySQL. Hasil penelitian ini adalah sistem informasi kasir berbasis Java Desktop pada Kedai Kopi Pejuang yang mempermudah bagian kasir untuk melakukan pendataan serta pembuatan laporan secara akurat.
\end{abstract}

Kata Kunci: Sistem Informasi, Java, MySQL, Kasir

\begin{abstract}
The warrior coffee shop which is located on jl. The beauty of the 1D highway, South Jakarta. The cashier information system at the warrior coffee shop is still done manually, managers find it difficult to calculate the value of income and expenses. By utilizing current information technology that can be combined with a computerized system so that it can help employee performance so that they can work effectively and efficiently. The research method that the author uses is Grounded Research, in general it is development and research in the field of technology. The purpose of the research is to design the use of the cashier information system and make it easier for the shop to manage transaction data and stock items, the cashier information system uses the JAVA programming language and also uses Xampp and Mysql. The results of this study are a Java desktopbased cashier information system at Kedai Kopi Pejuang which makes it easier for the cashier to collect data and make reports accurately.
\end{abstract}

Key Word: Information System, Java, MySQL, Cashier

\section{PENDAHULUAN}

Teknologi Informasi (TI) saat ini berkembang dengan sangat cepat. Dampak dari perkembangan teknologi informasi tersebut memberikan sebuah kemudahan bagi masyarakat dalam memenuhi segala kebutuhannya. Untuk memudahkan masyarakat dalam melakukan setiap aktivitas dan kebutuhannya, merupakan tantangan bagi para pengusaha dan pelaku bisnis untuk dapat memberikan pelayanan semaksimal mungkin bagi para konsumennya, dengan menyediakan berbagai macam fasilitas yang memadai guna memenuhi kebutuhan mereka tersebut.

Pengelola kafe harus memperhatikan karyawan serta keuangan dengan banyaknya transaksi yang terjadi setiap hari, jika tidak dikelola dengan baik akan mengakibatkan kerugian yang disebabkan pengelola sulit menghitung nilai pemasukan dan pengeluaran. (Ikhda Arifah \& Noersasongko, 2015) memanfaatkan perkembangan teknologi informasi yang dapat dipadukan dengan sistem informasi yang dapat membantu kinerja para karyawan untuk dapat bekerja secara efektif dan efisien.

Dalam penelitian penulis menemukan masalah yang terjadi di kedai kopi pejuang seperti struk pembelian yang masih menggunakan sistem manual ,dan menu favorit Kopi Pejuang yang selalu kehabisan stok hal tersebut membuat pelanggan pergi meninggalkan kedai , masalah tersebut terjadi karena tidak ada rekapitulasi menu-menu yang sudah terjual maupun stok bahan baku yang sudah menipis (Kuncoro et al., 2015). 
Masalah tersebut dapat mengakibatkan kehilangan pelanggan serta mengganggu pendapatan kafe. Menu-menu favorit yang dapat terjual banyak justru tidak dapat tersedia, dan kesalahan penyajian juga merupakan pemborosan bahan baku dan waktu menunggu pelanggan.

Berdasarkan latar belakang masalah yang telah dijelaskan di atas maka rumusan masalah dalam penelitian ini adalah bagaimana sistem informasi kasir dikedai kopi pejuang masih kurang efisien karena masih dilakukan secara manual. Bagaimana dalam pembuatan laporan mengalami kesulitan dalam pengumpulan data karena penyimpanan dan mencatatannya masih bersifat manual.

Berdasarkan pembatasan masalah dan asumsi penelitian diatas, maka tujuan yang hendak dicapai melalui pembuatan penelitian ini adalah untuk meminimalisir terjadinya keterlambatan pembuatan laporan pada kedai kopi pejuang. Sistem informasi kasir di kedai kopi pejuang yang masih kurang efesien karena dilakukan secara manual menjadi terkomputerisasi.

\section{METODE PENELITIAN}

Metode penelitian yang digunakan metode grounded (Grounded Research) suatu metode penelitian yang mendasarkan diri kepada fakta dan menggunakan analisa perbandingan bertujuan untuk mengadakan generalisasi empiris, menetapkan konsep-konsep, membuktikan teori dan mengembangkan teori di mana pengumpulan data dan analisa data berjalan pada waktu yang bersamaan. (Haig, 2018)

\section{Metode Pengumpulan Data}

Metode yang penulis gunakan antara lain:

Studi Kepustakaan (Library Research)

Pengumpulan data dan informasi dilakukan dengan mempelajari literatur dan kutipan dari buku-buku, dan browsing melalui search engineering di internet. (P. J. Naik, 2013) jelas mengenai pelaksanaan sistem yang berjalan serta mencari dan mengumpulkan data yang dibutuhkan langsung dari sumbernya yaitu dengan pengamatan langsung terhadap penyeleksian news untuk melengkapi wawancara. (Bastian et al., 2018)

Observasi pada Kedai Kopi Pejuang diperlukan untuk mengetahui atau mendapatkan data yang tidak mungkin didapat dengan cara melakukan pengamatan secara langsung kelapangan mengenai pendataan barang.

\section{Wawancara}

Pengumpulkan data dengan metode wawancara ini bertujuan untuk mencari data agar lebih akurat (Koentjaraningrat, 2019). Wawancara dilakukan dikedai kopi pejuang dan yang menjadi objek penelitian dengan bapak Nahrul Hayat, S.Kom selaku kepala administrasi, dalam wawancara dengan beliau penulis dapat menyimpulkan beberapa point yang harus dilakukan oleh penulis untuk mengatasi masalah yang terjadi adapun permasalahannya sebagai berikut:

1) Bahwa alur pelayanan yang dilakukan oleh Kedai Kopi Pejuang adalah Admin mengisi kelengkapan datanya terlebih dahulu.

2) Penginputan data barang masih dilakukan dengan cara manual dan belum terkomputerisasi.

3) Sistem pembuatan laporan yang masih dilakukan secara manual.

\section{Langkah-langkah Pengembangan}

Metode yang digunakan yaitu metode pengembangan waterfalI. Model waterfall atau sering kali disebut sebagai classic life cycle adalah model pengembangan perangkat lunak yang menekankan fase-fase yang berurutan dan sistematis, dimulai dari spesifikasi kebutuhan konsumen dan berkembang melalui proses perencanaan (planning), pemodelan (modelling), pembangunan (construction), dan penyebaran (deployment), (Guntoro, 2020)

\section{Studi Lapangan (Field Research)}

\section{Observasi}

Observasi pada Kedai Kopi Pejuang dilakukan selama lima bulan (5) dimulai bulan Maret sampai Juli 2021 dengan bapak Nahrul Hayat untuk mendapatkan gambaran yang 


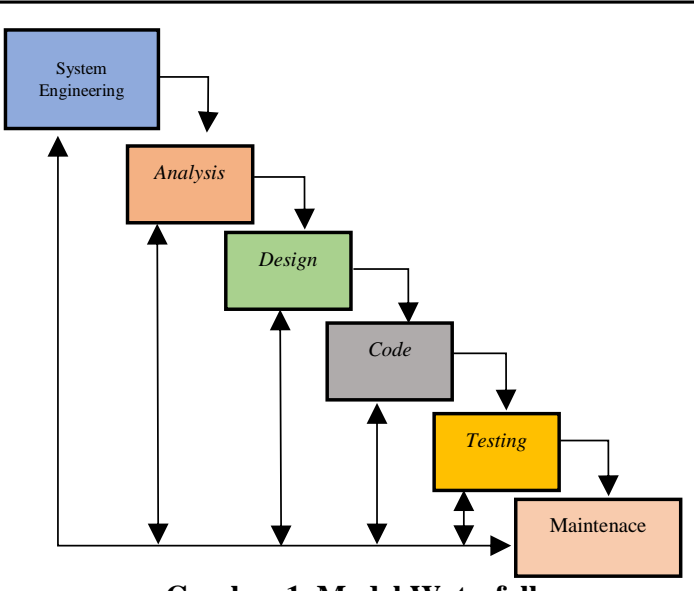

Gambar 1. Model Waterfall

\section{Pengumpulan Data}

Di dalam tahapan ini, persyaratan potensial dari aplikasi dianalisis secara metodis dan ditulis dalam dokumen spesifik yang berfungsi sebagai dasar untuk semua pengembangan di masa mendatang. Ini akan menghasilkan dokumen persyaratan yang menentukan apa yang harus dilakukan aplikasi, bukan bagaimana cara melakukannya.

\section{Analisis Data dan Proses (data analysis process)}

Kemudian sistem akan dianalisis untuk menghasilkan model dan logika bisnis yang akan digunakan dalam perancangan sistem informasi kasir pada kedai kopi pejuang dalam melakukan pengolahan data-datanya. Perangkat yang dimaksud adalah penggunaan DFD(Data Flow Diagram) untuk menyusun daftar input, proses dan output fungsi bisnis.(Ali, 2017)

\section{Perancangan Sistem (Design System)}

Tahap ketiga ini secara umum mencakup kepentingan desain teknis seperti bahasa pemrograman, lapisan data, layanan, dan sebagainya. Spesifikasi desain biasanya akan dibuat untuk menguraikan bagaimana logika bisnis yang tercakup dalam analisis akan diimplementasikan secara teknis.(S, 2012)

\section{Pengkodingan (Coding)}

Sumber kode yang sebenarnya akhirnya akan ditulis pada tahap keempat metode waterfall ini. Hal yang akan diterapkan mulai dari model, logika bisnis, hingga integrasi layanan yang ditentukan di tahap sebelumnya.
Pengujian (Testing)

Ketika tahap ni dilakukan, umumnya QA, beta tester, serta orang yang menguji aplikasi akan menemukan berbagai masalah dalam aplikasi yang harus diselesaikan. Melaporkan masalah sangat penting dalam tahapan ini. Tak jarang, mengulang atau merombak fase coding sebelumnya harus dilakukan agar semua bug yang ada dapat dihilangkan.

\section{Implementasi dan Maintenance}

tahapan terakhir dari metode pengembangan waterfall. Di sini software yang sudah jadi akan dijalankan atau dioperasikan oleh penggunanya. (Wang et al., 2014) Disamping itu dilakukan pula pemeliharaan yang termasuk :

a. perbaikan kesalahan

b. perbaikan implementasi unit sistem

c. peningkatan jasa sistem sesuai kebutuhan baru.

\section{HASIL DAN PEMBAHASAN}

Diagram konteks sistem informasi kasir kedai kopi pejuang adalah sebagai berikut :

\section{DIAGRAM KONTEKS}

Tampilan diagram kontek pada sistem informasi kasir di kedai kopi pejuang

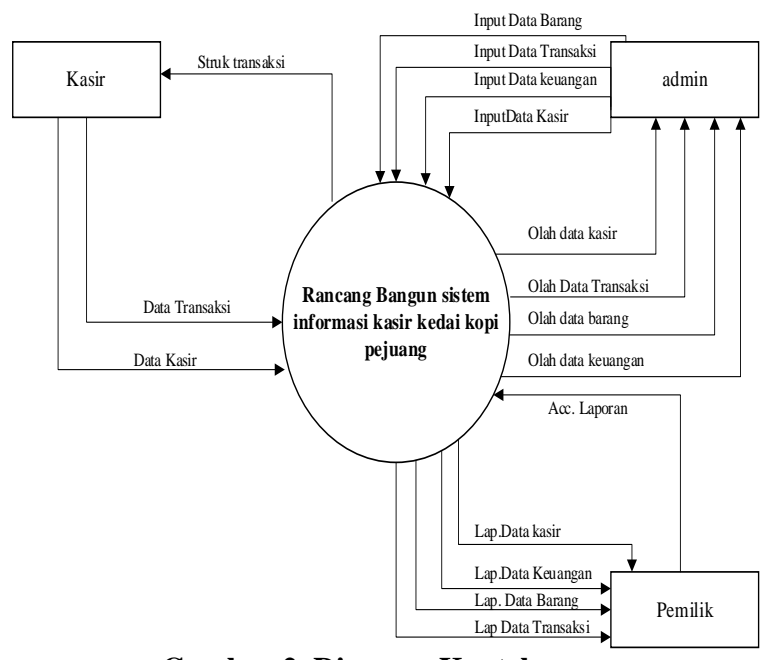

Gambar 2. Diagram Konteks

\section{Entity Relationship Diagram (ERD)}

Tampilan ERD pada sistem informasi kasir di kedai kopi pejuang 


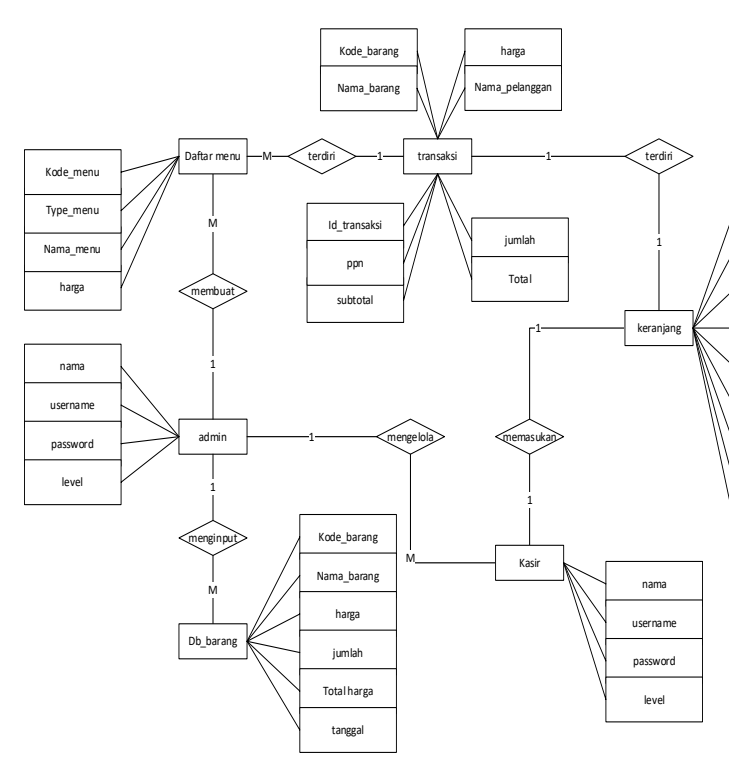

Gambar 3. Entity Relationship Diagram

\section{Normalisasi Tahap Kedua (2NF)}

Tampilan Normalisasi tahap kedua pada sistem informasi kasir di kedai kopi pejuang

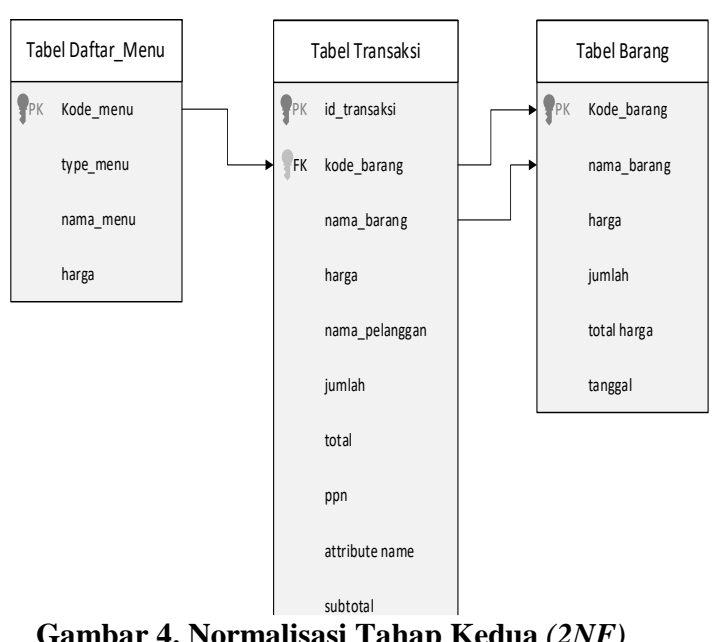

\section{TAMPILAN MENU LOGIN}

Tampilan login berisikan username, password dan level dari setiap user.

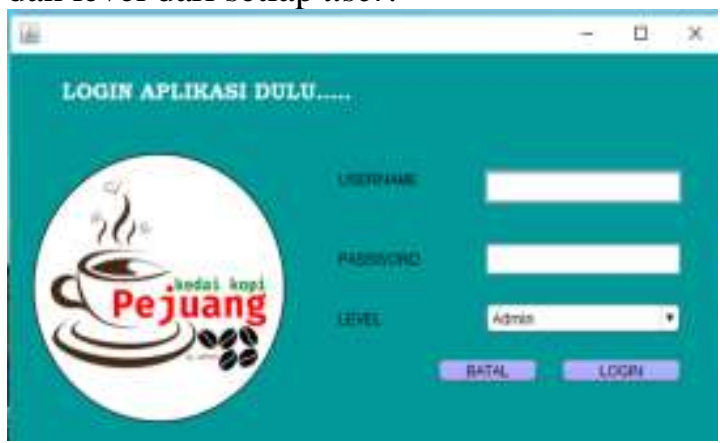

Gambar 5. Tampilan Menu Login
TAMPILAN MENU UTAMA ADMIN

Pada menu utama Admin terdapat beberapa pilihan menu antara lain: data barang, data kasir, data menu, riwayat dan logout.

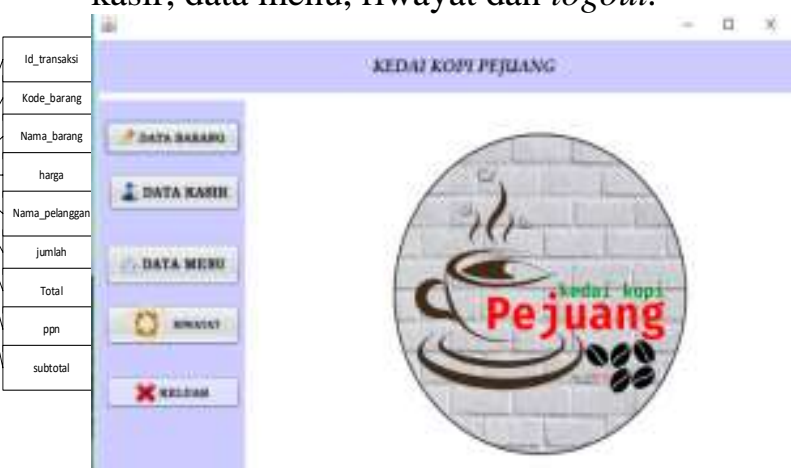

Gambar 6. Tampilan Menu Utama Admin

\section{TAMPILAN DATA BARANG}

Pada tampilan data barang terdapat table serta serta beberapa button untuk melakukan CRUD. Berfungsi untuk menambahkan data barang yang belum di input atau ada perubahan data pada data barang.

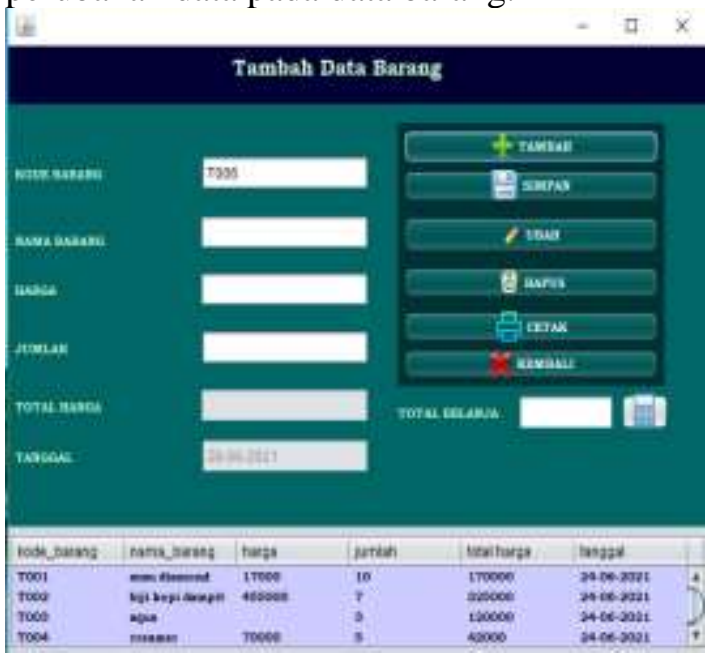

Gambar 7. Tampilan Data Barang

\section{TAMPILAN DATA KASIR}

Form data kasir berfungsi untuk menambahkan atau menghapus data kasir serta membuat username dan password untuk dapat login ke aplikasi.

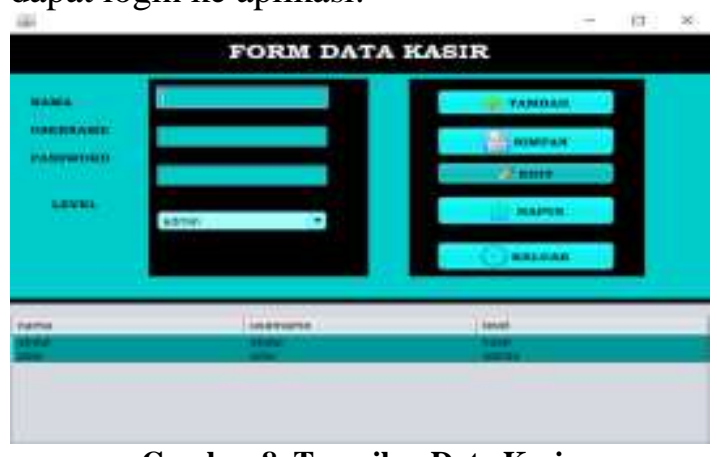

Gambar 8. Tampilan Data Kasir 
TAMPILAN TAMBAH MENU

Form tambah menu bertujuan untuk menambahkan menu makanan dan minuman yang akan di jual di kedai kopi pejuang.

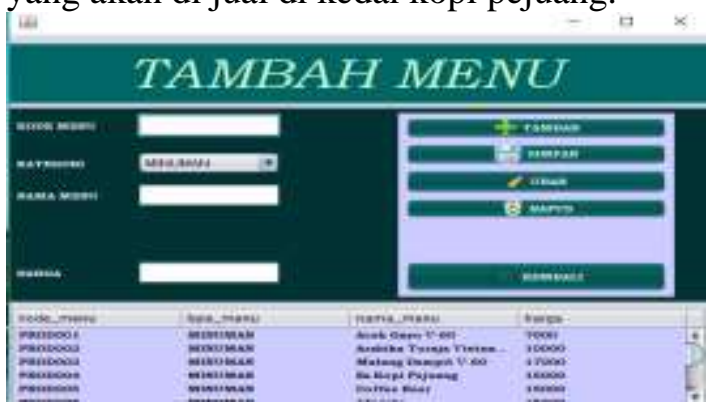

Gambar 9. Tampilan Tambah Menu

\section{TAMPILAN RIWAYAT TRANSAKSI ADMIN}

Form riwayat transaksi merupakan histori dari semua transaksi yang telah di lakukan oleh kasir dan di inputpada aplikasi.

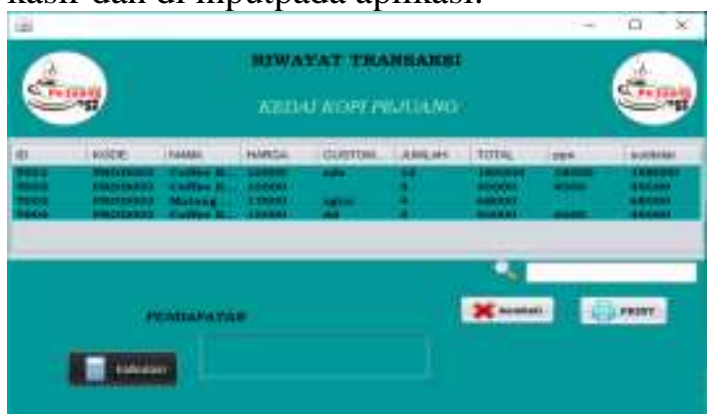

Gambar 10. Tampilan Riwayat Transaksi Admin

\section{TAMPILAN MENU KASIR}

Tampilan menu kasir terdapat beberapa menu pilihan yaitu transaksi, daftar menu dan riwayat transaksi.

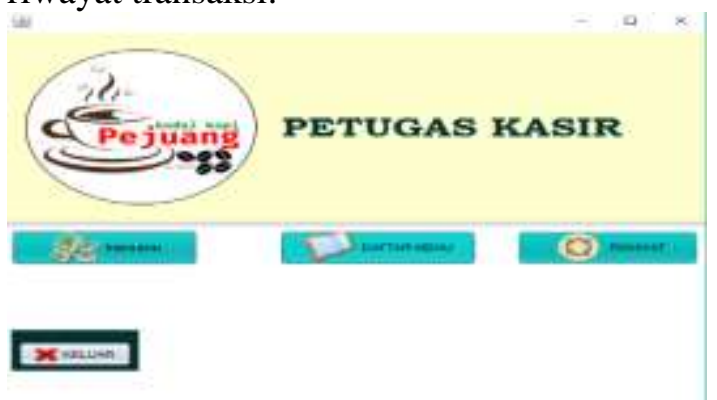

Gambar 11. Tampilan Menu Kasir

\section{TAMPILAN TRANSAKSI}

pada form transaksi kasir dapat mengisikan menu menu yang dipesan oleh pelanggan dan dapat dicetak untuk menjadi bukti pembelian/ struk belanja.

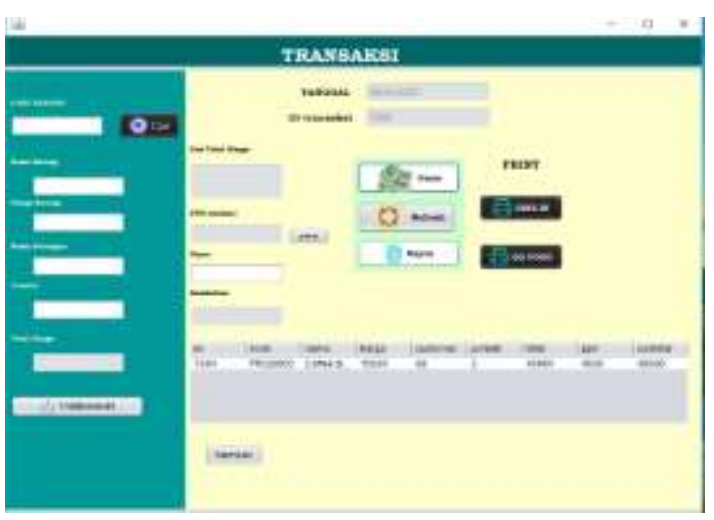

Gambar 12. Tampilan Transaksi

\section{TAMPILAN DAFTAR MENU}

Form daftar menu menampilkan data menu menu yang telah di input kedalam sistem kasir.

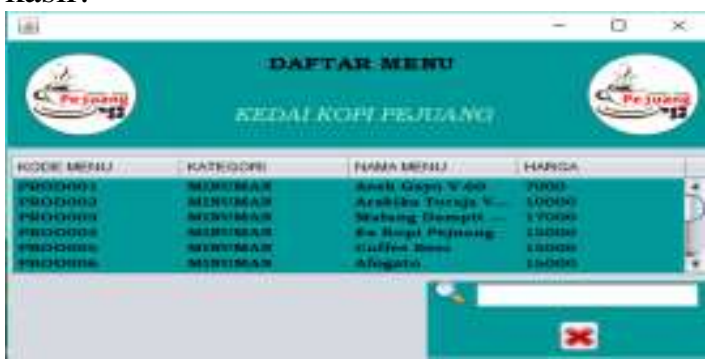

Gambar 13. Tampilan Daftar Menu

\section{TAMPILAN LAPORAN TRANSAKSI ONLINE}

Tampilan struk transaksi untuk transaksi melalui online, dengan penambahan pajak $10 \%$.

KOPI PEJUANG

\begin{tabular}{|c|c|c|c|}
\hline 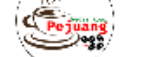 & \multicolumn{3}{|c|}{ JAKARTA-SELATAN } \\
\hline \multicolumn{2}{|c|}{ Jakarta ,30 Juli 2021} & CUSTON & agus \\
\hline \multicolumn{4}{|c|}{ GO-FOOD } \\
\hline MENU & HARGA & JUMLAH & SUBTOTAL \\
\hline Coffee Beer & 15000 & 3 & 45000 \\
\hline Mie Do It Egg & 10000 & 4 & 40000 \\
\hline SUBTOTAL & & & 85000 \\
\hline PAJAK(10\%) & & & 8500 \\
\hline TOTAL & & & 93500 \\
\hline Go-Food & & & 93500 \\
\hline
\end{tabular}

Gambar 14. Tampilan Laporan Transaksi Online

TAMPILAN LAPORAN DATA BARANG Laporan semua data barang yang dijual dikedai kopi pejuang, 


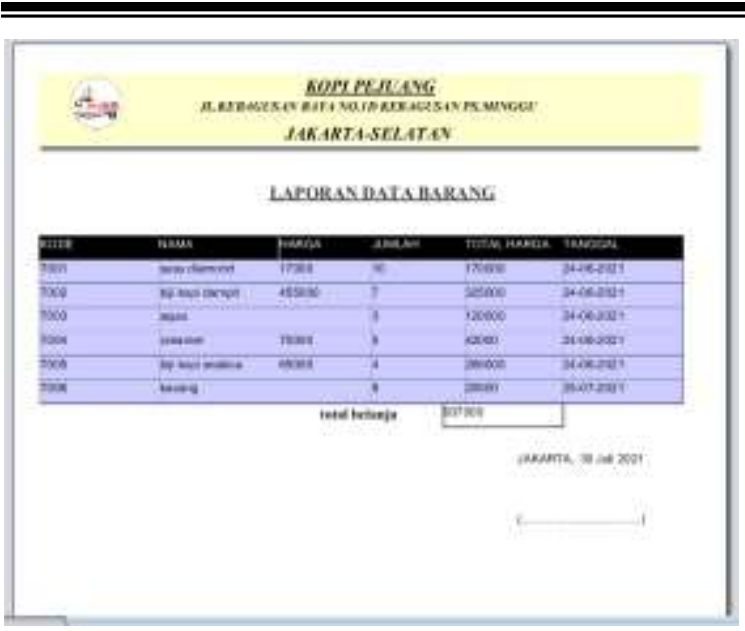

Gambar 14. Tampilan Laporan Data Barang

\section{SIMPULAN DAN SARAN}

Berdasarkan dari analisis, penelitian dan perumusan masalah yang ada, maka simpulan yang dapat diambil diantaranya:

Dengan dibangunnya sistem informasi kasir maka kendala yang dihadapi kedai kopi pejuang yaitu mencetak struk serta membuat laporan menjadi terkomputerisasi.

Dengan adanya sistem ini yang sudah terkomputerisasi, pimpinan maupun bagian keuangan tidak lagi mengalami kesulitan dalam memperoleh laporan. Kesalahan dalam pencatatan dapat diperkecil, dengan adanya sistem informasi ini. mempermudah para admin dan kasir dalam proses transaksi dan pembuatan laporan.

Penulis menyadari bahwa sistem informasi kasir Kedai Kopi Pejuang ini masih memiliki banyak kekurangan. Penulis berharap sistem ini dapat dikembangkan lebih baik lagi. Maka penulis memberi saran sebagai berikut:

Perlu adanya pemeliharan program aplikasi serta penyempurnaan, maka evaluasi dalam jangka waktu dekat diperlukan. Misalnya dalam satu bulan sampai satu tahun ini, sehingga dapat menjadikan tolak ukur keberhasilan dari aplikasi ini. Ataupun juga sebagai acuan dalam pengembangan pada sistem yang lebih baik lagi.

Menempatkan penggunaan yang telah memahami prosedur pemakaian program sistem informasi Kasir, sehingga menghindari terjadinya kesalahan dalam pengoperasian yang mengakibatkan terhambatnya kegiatan operasional pada bagian penjualan Di kedai kopi pejuang. Perlu dilakukan data (back up) secara berkala untuk menghindari rusak atau hilangnya data ketika perangkat keras maupun perangkat lunak mengalami masalah.

\section{DAFTAR PUSTAKA}

Ali, U. (2017). Pengertian Diagram Konteks dan Data Flow Diagram (DFD). WordPress.

Bastian, I., Winardi, R. D., \& Fatmawati, D. (2018). Metoda Wawancara. Metoda Pengumpulan Dan Teknik Analisis Data, September 2018.

Guntoro. (2020). Metode Waterfall : Pengertian, Tahapan, Contoh, Kelebihan dan Kekurangan. Https://Badoystudio.Com/, 2020.

Haig, B. D. (2018). Grounded theory method. In Studies in Applied Philosophy, Epistemology and Rational Ethics. https://doi.org/10.1007/978-3-03001051-5_5

Ikhda Arifah, U., \& Noersasongko, E. (2015). Rancang Bangun Aplikasi Point Of Sales (POS) Berbasis Java Desktop Yang Terintegrasi Web Mobile Pada Rumah Makan Spesial Sambal Semarang. Rancang Bangun Aplikasi Point Of Sales (POS) Berbasis Java Desktop Yang Terintegrasi Web Mobile Pada Rumah Makan Spesial Sambal Semarang.

Koentjaraningrat, K. (2019). Metode-metode Wawancara. Antropologi Indonesia. https://doi.org/10.7454/ai.v0i6.10460

Kuncoro, D. W., Purnama, bambang eka, \& Wardati, indah uly. (2015). Sistem Kasir Dan Pendataan Stok Barang Pada Tata Distro Pacitan. Journal Speed, 7(1).

P. J. Naik, D. V. P. and P. S. D. (2013). Pelagia Research Library. Der Chemica Sinica.

S, R. (2012). System Analysis and Design. Journal of Information Technology \& Software Engineering. https://doi.org/10.4172/2165-7866.s8e001

Wang, Y., Deng, C., Wu, J., Wang, Y., \& Xiong, Y. (2014). A corrective maintenance scheme for engineering equipment. Engineering Failure Analysis. https://doi.org/10.1016/j.engfailanal.20 13.10.006 